\title{
Narrativas autobiográficas e sua presença em periódicos A1
}

\author{
Autobiographical narratives and their presence in A1 journals
}

\author{
Sarah Silva Garcia ${ }^{1}$ \\ Tania Regina de Souza Romero ${ }^{2}$
}

\section{Resumo}

O presente trabalho tem por objetivo discutir o papel de narrativas autobiográficas para a formação docente e investigar como os periódicos A1 de educação têm tematizado esse recurso. Para isso, a título e contextualização, primeiramente retomamos a história da formação docente e discorremos sobre a formação docente crítico-reflexiva, com base em autores relevantes da área. Em seguida, abordamos a contribuição das narrativas autobiográficas para a formação docente, numa perspectiva em que as narrativas auxiliam como método de pesquisa para rever os caminhos e descaminhos e atribuir significados, além de serem fundamentais para a formação e (auto)formação do professor, pois possibilitam o deslocamento entre passado, presente e futuro e, por isso, é um suporte importante para o conhecimento e o reconhecimento (SOUZA, 2013). Por último, adotando metodologia bibliográfica, identificamos artigos publicados em revistas A1 de educação que tematizam as narrativas autobiográficas para a formação docente. Apesar de termos encontrado poucos artigos em um espaço de seis anos, as publicações ratificam a relevância da narrativa (auto)biográfica para o desenvolvimento crítico do docente.

Palavras-chave: Autobiografia; Formação docente; Prática reflexiva; Educação.

\begin{abstract}
This contribution aims at discussing the role of autobiographical narratives in teacher education and investigate how A1 journals in Education have thematized it. For such, with the purpose of contextualizing the theme, we start by reviewing the history of teacher education and show the relevance of autobiographical narratives for teacher education, stressing their role as research method to rethink one's own paths and revealing meanings, besides being crucial for teacher (self)education, since they allow movement through past, present and future. As such, it constitutes an importante aid for self-knowledge (SOUZA, 2013). At last,

\footnotetext{
${ }^{1}$ Sarah Silva Garcia, mestre, Colégio Rochel COC, Ouro fino e Colégio Monte Sionense, Monte Sião, MG, Brasil, sasilvagarcia@hotmail.com

2 Tania Regina de Souza Romero, doutora em Letras e Professora do Programa de Pós-Graduação em Educação da UFLA, Lavras, MG, Brasil, taniaromero@ufla.br
} 


\section{OO DEVIR EDUCAÇÃO}

ISSN: 2526-849X

by adopting a bibliographic methodology, we examine articles published in A1 journals which have (auto)biographies as center point for the process of teacher education. In spite of having found few articles published in the period of six years, the publications reinforce the relevance of the (auto)biographical narratives for the critical development of teachers.

Key-words: Autobiography; Teacher education; Reflective practice; Education

\section{Introdução}

Este artigo tem como objetivo discutir o papel de narrativas autobiográficas na formação docente e posteriormente investigar como elas estão sendo tematizadas em revistas A1 de educação.

Primeiramente, a título de contextualização, baseando-nos, principalmente em Saviani (2005, 2009) e Tanuri (1979, 2000), abordamos, de maneira sucinta, alguns momentos importantes para a formação de professores no Brasil para contextualizar historicamente os desenvolvimentos na área. Depois, tratamos sobre a formação docente reflexiva, segundo Fávero et. al (2013), Alarcão (2005, 2007), Celani (2004), Perrenoud (1999), Ghedin (2005) e Freire (1996), trazendo não somente o conceito, mas também o contraponto a perspectivas tecnicistas que por muito tempo pautaram o preparo para a docência dessa formação.

No terceiro tópico, abordamos brevemente o contexto educacional, o qual nos mostra que desde muito tempo valorizou-se a tecnicidade contraposta à reflexão crítica (Oliveira, 2018). Depois, fundamentadas em Nóvoa (1988), Abrahão (2003) e Reichmann e Romero (2019), expomos as contribuições das narrativas para a formação docente, numa perspectiva de que elas servem como método de pesquisa e contribuem para uma formação que envolve os educandos no processo.

Por fim, enfocamos oito artigos publicados encontrados em periódicos classificados como de alto impacto pela CAPES (Coordenadoria de Aperfeiçoamento de Pessoal de Nível Superior) na área de Educação, destacando alguns pontos que acreditamos serem relevantes para professores em formação inicial ou continuada.

Pensamos que este trabalho se faz importante visto que, apesar de as narrativas serem utilizadas na formação de professores há mais de 30 anos, essa abordagem ainda ser fértil para provocar reflexões especialmente pertinentes quando se discute as crescentes e inesperadas demandas educacionais de nossos tempos. 


\section{Momentos importantes da formação de professores no Brasil}

Neste primeiro tópico, visando contextualizar o tema, pretendemos desvelar de forma sucinta alguns momentos importantes sobre a formação de professores no decorrer da história, dando ênfase à formação docente no Brasil.

De acordo com Saviani (2009) a formação docente foi iniciada por Comenius, no século XVII e a implantação do ensino voltado à formação docente foi estabelecida por São João Batista de La Salle em 1684, no que ficou conhecido como Seminário dos Mestres.

Porém, conforme história o autor, foi apenas no século XIX que o problema da instrução popular se acentuou, pois o ensino primário foi democratizado, ou seja, todas as camadas sociais poderiam ter acesso ao ensino. Além disso, nessa época foram criadas as Escolas Normais com o objetivo de preparar professores.

Conforme explica Tanuri (2000, p. 62), a implementação das escolas destinadas à formação de professores "está ligada à institucionalização da instrução pública no mundo moderno, ou seja, à implementação das ideias liberais de secularização e extensão do ensino primário a todas as camadas da população". Essas escolas normais eram responsáveis por transmitir o saber sobre as técnicas e normas primordiais à formação dos professores responsáveis pelo ensino elementar.

A primeira Escola Normal institucionalizada no Brasil aconteceu na Província do Rio de Janeiro, sob a lei $n^{0} 10$, de 1835 , porém foi fechada em 1849 por não produzir os resultados esperados. Essas escolas ofereciam um curso de nível primário, básico, limitado, sem ensino de didática, sem momentos práticos e exclusivamente teórico, voltado para estudantes que apenas sabiam ler e escrever (TANURI, 1979). Assim, o propósito das Escolas Normais era o de difundir na sociedade um tipo de moral universal, voltado para a civilidade e a ordem, e não para uma formação intelectual dos professores. 


\section{OO DEVIR EDUCAÇÃO}

ISSN: 2526-849X

Tanuri (1979) aponta a falta de êxito das escolas normais do Brasil, lamentando que nos primeiros 50 anos do Império, as poucas escolas normais do Brasil, pautadas nos moldes de medíocres escolas primárias, não foram além de ensaios rudimentares.

Somente após 1870 as escolas atingiram certa estabilidade (Tanuri, 2000), com o Decreto $\mathrm{n}^{\mathrm{o}} 27$ de 12 de março de 1890, desenvolvido pelo Estado de São Paulo, o qual objetivava realizar uma grande reforma da instrução pública.

De acordo com o decreto, os reformadores entendiam que as Escolas Normais deveriam modificar seus conteúdos curriculares e dar ênfase ao preparo prático, e devido a esse último, criaram a Escola-Modelo, anexada à Escola Normal, a qual tinha como foco preparar os alunos sob um modelo prático, deixando à parte o ensino teórico (SAVIANI, 2005).

A década de 1930 foi marcada por uma nova fase da formação de professores. Em 1932, Anísio Teixeira, um importante educador da época, implantou o Instituto de Educação do Distrito Federal, e em 1933 foi fundado o Instituto de Educação de São Paulo, por Fernando de Azevedo. Ambas as iniciativas foram orientadas por um movimento educacional renovador, denominado Escola Nova (SAVIANI, 2005 e 2009).

As novas ideias referentes à formação de professores baseavam-se na "experimentação pedagógica concebida em bases científicas" (SAVIANI, 2005, p. 16). Em outros dizeres, a Escola Nova apareceu com o objetivo de preparar os professores por meio de um ensino profissional que os formasse integralmente para a profissão, com disciplinas específicas para esse trabalho.

Importante salientar que as ideias fundamentadas na Escola Nova foram extremamente significativas para uma nova perspectiva da formação de professores, pois, anteriormente, frente ao modelo das Escolas Normais, o ensino priorizava a transmissão de conhecimentos pré-determinados nos currículos. Além disso, os conhecimentos advindos da escola eram vistos como parte externa aos alunos e esses fatores, consequentemente, contribuíam para desenvolver indivíduos passivos diante da aprendizagem, como lhes fora atribuído um papel de "depósito de informações", já que eram forçados a aprender conteúdos que não lhes eram necessariamente interessantes (MARTINS e DUARTE, 2010).

Por outro lado, com a Escola Nova, os alunos tinham "protagonismo inconteste" (MARTINS e DUARTE, 2010, p. 65), isto é, o foco não era mais o conteúdo, mas o aluno. Dessa maneira, os conteúdos ministrados dependiam da intenção/interesse dos alunos, em que 
a preocupação da educação centrava-se no desenvolvimento de estudantes capazes de irem em busca de conhecimento.

Em consequência do golpe militar de 1964, houve a reformulação do ensino superior, por meio da lei 28 de novembro de 1968, n $^{0}$ 5.540/68 e houve a alteração na denominação dos ensinos primário e secundário para primeiro grau e segundo grau, sob a lei de 11 de agosto de 1971, $\mathrm{n}^{0} 5.692 / 71$, e por conta dessas mudanças foram extintas as Escolas Normais dando lugar a Habilitação Específica de $2^{\circ}$ grau para o exercício do magistério de $1^{\circ}$ grau (Saviani, 2005). Diante dos problemas causados por esse modelo educacional, o Governo, em 1982, criou o projeto Centros de Formação e Aperfeiçoamento do Magistério.

Em 1996, a nova LDB ofertou uma nova alternativa para a formação de professores, aos cursos de pedagogia e licenciatura, em que inseriu os Institutos Superiores de Educação e as Escolas Normais Superiores. Nesse âmbito, foi estabelecida a combinação entre teoria e prática, o que concebia capacitar os professores "em serviço e o aproveitamento da formação e de experiências anteriores em instituições de ensino" (SHEIBE, 2008, p. 49).

Por conta da expansão aligeirada dos cursos de formação inicial, pode-se pensar que não houve muitos critérios de qualidade, pois o sistema de ensino estava focando na quantidade, na ampliação das estatísticas da formação superior, e isso gerou outro problema, pois reduzia-se o trabalho pedagógico e corrompia-se a identidade dos professores do magistério (SHEIBE, 2008).

Resumidamente, a LDB atribuiu a responsabilidade de formação de professores aos Institutos Superiores de Educação, ao determinar que os sujeitos optassem pela formação, preferencialmente, neles. Passou-se, então, às Universidades a formação de professores para aqueles que tinham como intuito serem supervisores educacionais ou diretores.

Ao passar por esses momentos históricos da formação docente, percebemos que, apesar de todas as tentativas formativas, há ainda grandes carências e problemas na elaboração das políticas educacionais para realizar uma formação adequada para as necessidades que se apresentam. Por isso, vários educadores advogam em favor de uma formação que contemple teoria e prática, trabalhadas concomitantemente, em que os profissionais em formação inicial ou continuada sejam preparados a trabalhar de forma articulada à realidade (SAVIANI, 2005 e 2009; MAIA, MEDRADO e REICHMANN, 2018).

Para destacar esse enfoque na formação de professores, trazemos a seguir a questão da formação de professores críticos e reflexivos, capazes de atuarem em seu campo profissional 
e se (des)construírem por meio de reflexões e questionamentos sobre seu próprio contexto e sobre suas experiências vividas.

\section{Formação de professores reflexivos}

Atualmente, o contexto educacional, especificamente em relação à formação de professores, tem indicado novos desenvolvimentos. Dentre eles, destacamos nesse tópico a relevância à análise das próprias experiências. Entendemos que, assim, o professor em formação inicial ou continuada poderá refletir e interagir com situações/acontecimentos de sua prática. Diante dessa questão, dedicamo-nos a levantar alguns pontos sobre a preocupação quanto à formação de professores reflexivos frente a suas práticas pedagógicas.

Vimos no tópico anterior inúmeras tentativas em melhorar a questão da formação de professores. Apesar de algumas tentativas frustradas, para iniciar esse tópico, destacamos um dos pensamentos de Anísio Teixeira (1985), importante educador, fundador da Escola Nova. O educador advoga, basicamente, por uma pedagogia da práxis, ou seja, uma pedagogia de ação, que propõe um ensino capaz de desenvolver nos sujeitos professores, a capacidade de (re)pensar e agir sobre sua prática docente.

Teixeira (1985, p. 388) defende que a educação deva ser “[...] um processo de cultivo ou de cultura, há de ser sempre algo em permanente mudança, em permanente reconstrução, a exigir, por conseguinte, sempre, novas descrições, análises novas e novos tratamentos”. Diante dessas colocações, ponderamos que uma formação baseada nesses preceitos seria ideal para nós professores, já que é entendida como um processo que pressupõe mudanças, que se desenvolve em meio a construções, desconstruções e reconstruções.

O conceito de professor reflexivo, segundo Fávero et al. (2013) surgiu nos Estados Unidos, em contraposição às ideias do tecnicismo, as quais diminuíam o profissional docente a um mero aplicador de técnicas. Contrariamente à concepção tecnicista, Alarcão (2007, p.41) afirma que a concepção de professor reflexivo "baseia-se na consciência da capacidade de pensamento e reflexão que caracteriza o ser humano como criativo e não como mero reprodutor de ideias e práticas que lhe são exteriores". 
Celani (2004) argumenta que o professor precisa traçar novas metas, atualizar seus conteúdos, mas que também reflita sobre os "velhos mapas", pois é partir da reflexão sobre o que os velhos mapas indicam que podemos questionar e elaborar novos entendimentos por meio da contestação e conflitos. Essa colocação da autora nos remete a pensar que, revisitar as experiências e os acontecimentos para questionar e, consequentemente, se (re)modelar, faz-se fundamental para o desenvolvimento de um docente crítico perante sua prática pedagógica, em constante formação.

Diante dessa colocação, deve-se frisar, também pautadas em Celani (2004), que não basta o docente rememorar os "velhos mapas" e/ou conhecer "novos mapas", ou melhor, ter acesso às antigas ou novas teorias e conhecimentos, mas também dirigir-se para além do superficial, para poder vivenciar, sentir, apropriar-se das novas teorias, conceitos, saberes e conhecimentos.

Os Parâmetros Nacionais Curriculares (PCN) de língua estrangeira, a propósito, trazem uma colocação que se insere nesse contexto, expondo a necessidade do professor se envolver "[...] em um processo de reflexão sobre o seu trabalho em sala de aula. Essa reflexão é entendida como o modo mais eficiente para que as práticas em sala de aula sejam questionadas e alteradas [...]”. (BRASIL, 1998, p. 109)

Em meio a essas afirmações, podemos dizer que a profissionalização do sujeito professor e sua construção como um sujeito crítico podem e devem ser desenvolvidas por meio de uma prática reflexiva contínua. Perrenoud (1999, p. 10) já defendia anteriormente que uma prática reflexiva se insere na rotina, mas não uma "rotina sonífera; uma rotina paradoxal, um estado de alerta permanente", e vai além, afirmando que esse movimento dinâmico de reflexão exige "disciplina e métodos para observar, memorizar, escrever, analisar após compreender, escolher opções novas".

Cabe ressaltar que, ao refletir sobre a prática, o docente toma ciência do seu trabalho, além de passar a conhecer melhor a si mesmo. Ghedin $(2005$, p. 141), complementa essa afirmação, argumentando que "[...] ao construirmos o conhecer de um dado objeto, não é somente ele que se torna conhecido, mas essencialmente o próprio sujeito, isto é, o conhecimento de algo é também, simultaneamente, um autoconhecimento". Assim, alinhamonos a vários acadêmicos, tais como Zeichner (2008), Almeida e Gimenez (2010), Oliveira (2018) e Romero e Casais (2019) no entendimento que, ao refletirmos sobre nossas 
experiências, compreendemos tanto o fazer pedagógico, quanto o nosso ser, nossas identidades construídas continuamente ao longo da vida.

Outro ponto importante a se pensar quanto à relevância da formação docente reflexiva é que, ao fazer esse exercício contínuo de questionamentos e crítica sobre a própria prática, o sujeito se informa e se inteira sobre todo o contexto escolar, isto é, se posiciona de maneira ativa frente ao processo educacional. Ao contrário do professor tecnicista, o professor reflexivo não é mero transmissor de conteúdos, ele compreende as necessidades de seus alunos, contextualiza suas aulas em relação à comunidade escolar e ainda trabalha como mediador de conhecimento, ajudando seus alunos a se desenvolverem também como sujeitos reflexivos, que são capacitados a produzir saberes. Em relação a essa afirmação, Alarcão (2005, p.176) reconhece que

Os professores desempenham um importante papel na produção e estruturação do conhecimento pedagógico porque refletem, de uma forma situada, na e sobre a interação que se gera entre o conhecimento científico [...] Desta forma, têm um papel ativo na educação e não um papel meramente técnico que se reduza à execução de normas e receitas ou à aplicação de teorias exteriores à sua própria comunidade profissional (ALARCÃO, 2005, 176).

Assim sendo, acreditamos que seja necessário que o professor seja reflexivo, participante e dinâmico no processo de ensino-aprendizagem, buscando sempre aliar as teorias à realidade e às necessidades de seus educandos.

Contudo, cabe destacar que o mais importante nessa tarefa de refletir sobre a prática, é que "a reflexão seja um instrumento dinamizador entre teoria e prática" (FREIRE, 1996, p. 39). É imprescindível que a reflexão gerada sobre as experiências gere uma ação transformadora que seja contínua, permanente.

Mostramos no próximo item como o trabalho com narrativas autobiográficas se constitui em um instrumento que permite aos docentes escreverem sobre sua jornada, refletir sobre ela e transformar seus significados e paradigmas.

\section{As contribuições das narrativas para a formação docente}

Discorremos neste tópico ideias referentes às contribuições das narrativas autobiográficas como instrumento de formação docente, em que os professores, a partir das 
experiências relatadas e de uma análise crítica de sua biografia, podem atribuir novos sentidos a diferentes acontecimentos/situações e têm a oportunidade de modificar suas práticas e conceitos sobre ensinar e aprender.

Nóvoa (1988, p. 125) acentua a relevância de narrativas autobiográficas no processo de formação docente ao destacar que a partir do movimento de recuperar as memórias, refletir sobre os acontecimentos, se (re)formar e projetar o futuro "[...] o indivíduo constrói a sua memória de vida e compreende as vias que o seu património vivencial lhe pode abrir; ao fazêlo está a formar-se (emancipar-se) e a projectar-se no futuro".

Para enfocar essa temática, resenhamos, primeiramente, questões pertinentes ao contexto educacional, depois, sobre a relevância de uma formação docente crítica e reflexiva. Em seguida, uma breve concepção sobre identidade docente, e por fim, o conceito de narrativas autobiográficas em que nos apoiamos e suas respectivas contribuições para a formação docente.

No decorrer da história da educação, conforme mencionado anteriormente, por muito tempo os professores foram formados sob uma óptica homogeneizadora e superficial, em que o conhecimento era entendido como sinônimo de "passar informações", ou seja, uma formação em que não se visualizava as diferenças dos sujeitos, as suas heterogeneidades. Dessa forma, o conhecimento era considerado adquirido e não desenvolvido e construído por meio de questionamentos e reflexões. Esse enfoque foi deixado de lado, conforme apontamos nos dois primeiros itens deste artigo.

Nesse âmbito, entendemos que a formação docente deva ser um processo constante de desenvolvimento humano, em que os professores possam ser capazes de refletir sobre suas práticas pedagógicas. Além do mais, faz-se importante pensar num trabalho voltado para uma prática ativa e reflexiva, pois manipular a identidade de um professor seria o mesmo que abandonar seus saberes, suas motivações, suas perspectivas e suas formas de atuação como profissional que são construídos historicamente (SOUZA, 2016).

Assim, acentuando uma prática ativa e reflexiva, tomamos a ideia de Alarcão (2005, p.176) que afirma que a prática docente crítica e reflexiva é aquela em que o profissional "tem um papel ativo na educação e não um papel meramente técnico que se reduza à execução de normas e receitas ou à aplicação de teorias exteriores à sua própria comunidade profissional”. Desse modo, o profissional reflexivo não é o que apenas transmite conteúdos e informações, 
mas que se envolve com todo o contexto escolar (alunos, professores e outros funcionários) para pensar e (re)modelar sua própria prática conforme as necessidades.

Alarcão (2005) propõe pensar três pontos que explicitam o porquê de uma prática ativa e reflexiva: (a) os professores são sujeitos formados por saberes múltiplos, isto é, saberes científicos, saberes culturais, saberes religiosos, saberes profissionais, saberes experienciais, entre outros; (b) os saberes são sociais, pois, manifestam-se por meio das interações, por meio das relações entre professores e alunos, por exemplo; (c) estes professores são produtores de saberes, e são por meio desses saberes que eles constroem as suas práticas e projetos pedagógicos.

Assim, para que haja desenvolvimento e construção de saberes e conhecimentos, Tardif (2014, p. 230), argumenta que é imprescindível que o professor seja ator de sua prática, em que ele "assume sua prática a partir dos significados que ele mesmo lhe dá, um sujeito que possui conhecimentos e um saber-fazer provenientes de sua própria atividade e a partir dos quais ele a estrutura e a orienta".

Para mais, consideramos importante pensar na formação de profissionais da educação, para que ela não seja feita somente por meio de cursos profissionalizantes, técnicas e/ou métodos oferecidos em Universidades, mas um uma formação que estimule também a capacidade crítico-reflexiva dos professores, inserindo os futuros profissionais em seu campo de trabalho de forma a pensar e repensar as práticas pedagógicas, pois, como defende Freire (1996), aquele que se assume como está sendo e observa as razões de ser e do porquê estar sendo daquela forma, cada vez mais se torna capaz de mudar, e de promover-se.

Freire (1996, p.22) ainda agrega a ideia de que a prática docente crítica, "envolve o movimento dinâmico, dialético, entre o fazer e o pensar sobre o fazer, pois [...] É pensando criticamente a prática de hoje ou de ontem que se pode melhorar a próxima prática”.

Considerando essa perspectiva de formação, pesquisas como as de Nóvoa (1988; 1992), Almeida e Gimenez (2010), Romero (2008; 2010) e Souza (2013) têm abordado a relevância das narrativas autobiográficas para uma reflexão crítica e advogam ser essa abordagem uma fonte de investigação e desenvolvimento da prática docente. As pesquisas desses teóricos atentam para o ato de escrever sobre si, enfocando o percurso educativo, que permite não somente maior conhecimento e reflexão sobre a prática pedagógica, mas também como um espaço de ressignificação, compreensão e redirecionamento, favorecendo a formação docente. 
Acentuamos, ainda, a relevância de mediação de um educador para que a reflexão se dê de modo informado. Abrahão (2003) esclarece que "trabalhar com narrativas não é simplesmente recolher objetos ou condutas diferentes, em contextos narrativos diversos, mas, sim, participar na elaboração de uma memória que quer transmitir-se a partir da demanda de um investigador". Dessa maneira, a autobiografia é construída entre investigado e investigador.

De acordo com Romero (2010, p. 160), tanto o educador quanto o professor que elabora a autobiografia, devem "dirigir sua atenção para os efeitos das ações sócio-históricas, o impacto e relevância destes para a constituição do profissional, não para a 'neutralidade' esvaziada de sentidos". Com isso, podemos afirmar que as narrativas não são escritas espontaneamente, pelo contrário, devem seguir um norte para gerar as reflexões e os resultados esperados.

Além disso, o mediador é quem auxilia e elabora as perguntas, visualiza questões importantes que merecem aprofundamento para vencer possíveis inseguranças (ROMERO, 2008). O papel do mediador é fundamental para que os resultados esperados ocorram, é ele quem intervém "por meio de ações entre o conhecimento e o objetivo de aprendizagem" e age "de modo reflexivo, provocando reflexões para que transformações qualitativas ocorram" (ROMERO, 2010).

Assim, alinhando-nos às pesquisas que têm se desenvolvido no país e no exterior, consideramos relevante, ligar os acontecimentos/fatos da vida cotidiana e a participação de pessoas na vida do indivíduo que será estudado, para compreender de que maneira esses influenciaram e deram sentido à trajetória em sua formação docente. Dito de outra forma, entendemos que a autobiografia possibilita autoconhecimento e promove (des)construções e transformações na identidade docente, em que as experiências vividas, depois de orientadas por um mediador e observadas sob um olhar crítico, tornam-se fontes de conhecimento e formação.

Para Souza (2013), ainda, as narrativas autobiográficas são significativas para a formação e (auto)formação dos docentes, pois, ritualizam o tempo vivido e provocam um deslocamento no olhar entre o passado, o presente e o futuro, o que institui um importante suporte para o conhecimento e reconhecimento. $O$ autor acrescenta que as narrativas desnudam acontecimentos marcantes da vida, os quais dão sentido e significado à existência, 
o que permite afirmar que elas são extremamente significativas para compreender, reconhecer e atribuir significados aos contextos apresentados na própria narrativa.

As narrativas, portanto, propiciam um diálogo entre as dimensões da vida, em que o autor escreve sobre si e reflete sobre sua própria história, de modo a identificar os aspectos mais relevantes para dar sentido ao sujeito/profissional que se tornou. As experiências vividas e retratadas na autobiografia, então, são importantes para compreender o desenvolvimento e a construção da(s) identidade(s) docente, a qual, conforme já mostrava Nóvoa em seu texto seminal (1992, p. 16), não é "um dado adquirido, não é uma propriedade, não é um produto. A identidade é um lugar de lutas e de conflitos, é um espaço de construção de maneiras de ser e estar na profissão" (Nóvoa, 1992, p. 16).

Bauman (2005) entende que a identidade é um elemento individual do ser humano que se desenvolve, se constrói, se desconstrói durante toda a vida, a cada contexto em que o indivíduo se insere. Desse modo, o autor soma a ideia de que a identidade não é sólida como uma rocha, definitiva, mas sim revogável, e as escolhas e caminhos que os sujeitos tomam, e como esses agem, são possíveis condições para compor a identidade.

À vista disto, os seres humanos não possuem uma única identidade, pois são seres mutáveis, dinâmicos, contraditórios, que variam os pensamentos, que desenvolvem os valores e opiniões de acordo com o contexto que está inserido e os objetivos com que se confronta, por exemplo.

Diante dessas conceituações referentes às narrativas autobiográficas e à identidade, entendemos que o trabalho com as narrativas para a formação docente visa uma formação centrada na experiência, em que os profissionais são participativos no processo educacional, o qual, (re)pensa suas práticas e se compreende como um ser que está em constante processo de formação e desenvolvimento. Ademais, deve-se ter em conta que a identidade docente é atravessada por inúmeras contingências sociais, tecnológicas e culturais (ROMERO e CASAIS, 2019).

A intenção em voltar os olhos para si, em escrever narrativas, é o de voltar-se para a própria prática, o de mergulhar-se nas subjetividades e de compreender-se como se constituiu por meio das vivências no decorrer da vida, e a partir de então, refletir e se (des)construir, num processo permanente.

Por fim, se apreciarmos professores em posição ativa frente a sua profissão, o seu campo de trabalho será espaço para sensibilizar, modificar e inovar os materiais e projetos 
pedagógicos. Esse professor, logo, constrói-se como pesquisador contínuo da sua própria prática, preocupando-se em melhorá-la e aperfeiçoá-la.

Para entender como pesquisadores têm tematizado as narrativas autobiográficas como ferramenta de investigação na formação de professores, trazemos no tópico cinco estudos publicados em periódicos de classificação A1, segundo o critério Qqualis/CAPES. Antes, porém, explicitamos como empreendemos essa investigação.

\section{Metodologia}

O presente estudo foi realizado por meio de uma pesquisa bibliográfica que, de acordo com Bortoni-Ricardo (2008), é uma investigação que se origina de estudos em documentos e referências teóricas de obras publicadas, tais como livros, artigos científicos, dissertações e teses. Além disso, a pesquisa bibliográfica, segundo Oliveira (2008, p. 68) "busca informações fidedignas para se explicar em profundidade o significado e as características de cada contexto, em que encontra o objeto de pesquisa". Dessa maneira, buscamos averiguar, por meio dos periódicos classificados pela CAPES como A1, como as pesquisas têm abordado a formação docente tendo como ferramenta de investigação, as narrativas autobiográficas.

Especificamente, encontramos por meio da Plataforma Sucupira - ferramenta online da Capes - oito artigos da área de educação, de revistas A1, dos últimos seis anos. Acentuamos que foram selecionados apenas oito artigos, visto foi este o número de publicações sobre a temática em questão em revistas A1. Os artigos foram selecionados na Revista Educação da UFSM (2014, 2017), Educação e Realidade da UFRGS (2015, 2016 e 2018), Ciência e Educação (2015), Revista Portuguesa de Educação (2016), Revista Educação (2014, 2017) e Educação em Revista (2018). Vale ressaltar que consideramos apenas os artigos de periódicos A1, por entendermos que teriam maior impacto. Além do mais, todos os artigos aqui resenhados são da área de educação, com ênfase em formação de professores porque essa é a área em que atuamos.

\section{Narrativas em publicações A1 de educação.}


O primeiro trabalho, intitulado "Histórias de Vida e Saberes Docentes das Educadoras da Zona Urbana e Rural”, de Brito (2015), discutiu as narrativas de quarenta educadoras de Educação Infantil do Rio Grande do Norte, numa perspectiva experiencial e sociológica. Isto é, revelaram as trajetórias de vida pessoal e profissional, a partir dos saberes da experiência.

O projeto teve início em 2011, quando as educadoras responderam a um memorial/questionário que tinha como objetivo realizar uma análise tanto quantitativa quanto qualitativa. Para o primeiro tipo de análise, as professoras responderam sobre gênero, idade, nível de formação profissional, participação em eventos científicos e tempo de experiência. Para o segundo tipo de análise, responderam sobre a representação pessoal, vida familiar e escolar, escolha da profissão, formação docente e atuação docente.

Em um segundo momento, em 2012, houve um encontro para um debate sobre a formação docente, para tratar sobre a importância da formação continuada e apresentar os primeiros resultados da pesquisa. E por último, em 2013, Brito reuniu os resultados, articulando os contextos rural e urbano no artigo em questão.

Os resultados revelaram que as trajetórias de vida pessoal e profissional, a partir dos saberes da experiência, têm repercussões nas práticas pedagógicas, e sobre a análise quantitativa, mostraram grandes diferenças entre educadores da zona rural e zona urbana, principalmente no que se referiu à formação. Brito (2015) ressalta que o trabalho com narrativas precisaria ser um processo, não se dar de maneira única ou isolada.

O segundo artigo, "Saber da experiência e narrativas autobiográficas na formação inicial de professores de biologia”, de Gastal e Avanzi (2015), procurou investigar a formação de alunos de Licenciatura em Ciências Biológicas da Universidade de Brasília. As autobiografias produzidas revelaram o percurso de formação dos estudantes desde a educação básica até o estágio supervisionado, proporcionando a eles autorreflexão sobre esse percurso.

Diferentemente da pesquisa anterior, realizada por Brito (2015), que investigou a formação continuada, esta pesquisa propôs trabalhar com professores em formação inicial, e, diante desse trabalho, as pesquisadoras puderam constatar que a reflexão realizada a partir da narrativa permitiu que os estudantes ressignificassem as vivências anteriores. Além disso, destacaram também a relevância da narrativa como método de pesquisa, o que acarretou na valorização da subjetividade, ou seja, reconheceram a importância da subjetividade para gerar conhecimento. 
A pesquisa de Bragança e Perez (2016), em artigo com o título "Formação Continuada em Escolas de Tempo Integral: narrativas de professoras”, buscou explanar, por meio da narrativa de três professoras, o contexto vivido nas escolas e os movimentos de luta entre as políticas de formação instituídas e os caminhos produzidos por elas. Em outras palavras, por meio das narrativas, as professoras contaram a relação da prática e da formação docente. Os resultados indicaram as dificuldades e potencialidades envolvendo tanto a formação docente quanto o movimento de reflexão crítica sobre o trabalho docente.

Baladeli, Borstel e Ferreira (2016), realizaram uma pesquisa denominada "Identidades docentes e diferença no discurso de professores de Língua Inglesa em formação inicial”, veiculada na Revista Portuguesa de Educação, que teve como enfoque identificar, por meio do discurso de seis professores de língua inglesa, de duas Universidades públicas do Paraná, quais sentidos estes sujeitos construíam sobre a sua profissão e quais as identidades construídas em meio à influência da carreira profissional escolar.

Com base nos resultados, as pesquisadoras entenderam que as identidades estão em constante construção e que programas de formação, como o Programa Institucional de Bolsas de Iniciação a Docência - PIBID auxiliam no processo de reflexão, seja ele de um grupo, ou sobre si mesmo.

Uma pesquisa realizada por Rios, Barros e Vieira (2017), denominada "Narrativas de vida e formação de professores gays: (auto) biográficas acerca do estranho que habita em mim" teve como objetivo analisar, por meio de narrativas (auto)biográficas, as histórias de vida de professores homossexuais, para compreender as particularidades dos processos de formação, implicados em suas histórias de vida e formação, ou seja, entrelaçaram as histórias de vida, as trajetórias escolares, acadêmica e profissional às vivências subjetivas destes professores.

Além disso, procuraram responder questões como "de que maneira o ambiente escolar lida com professores cuja orientação sexual é a homossexualidade?" e "como as questões de gênero e sexualidade, vivenciadas por professores gays, influenciam em seu processo de formação e em sua prática docente?”.

Os resultados apontaram para a necessidade de terem-se políticas públicas que rompam com a formação de hierarquias, intolerâncias e padrões heteronormativos, visto que a escola, de acordo com as narrativas dos professores, produz e reflete as concepções de gênero e sexualidade. Além disso, puderam concluir que há a necessidade de práticas pedagógicas 
pautadas no respeito ao direito do outro, a fim de construir um olhar mais amplo em torno da diversidade.

Para eles, o resultado da pesquisa foi positivo, pois, reconheceram que as narrativas (auto)biográficas contribuíram para uma maior compreensão do fenômeno da homossexualidade no contexto escolar, ao tempo em que possibilitou aos professores um momento de reflexão e auto formação.

O sexto artigo, chamado "Desenvolvimento Profissional Docente: A trajetória de uma professora supervisora no PIBID”, realizado por Nascimento e Barolli (2018), publicado na Educação em Revista, investigou e refletiu sobre a trajetória de uma professora de física que atuava como supervisora do PIBID. Para a realização da pesquisa, os estudiosos fizeram um roteiro de questões que abarcaram os seguintes temas: trajetória pessoal, profissional e de formação, contexto do subprojeto, condução do ensino, sustentação da aprendizagem e formação e atualização.

Os resultados contribuíram para sugerir mudanças na rotina da supervisora e para o seu desenvolvimento profissional. Vale ressaltar que, nessa pesquisa, ficou clara a ligação e/ou a dependência do indivíduo e da realidade/de seu contexto para com as práticas que esse mesmo indivíduo realiza. Conforme argumentam os autores, o que o sujeito é, e o que ele vivencia, impulsiona a sua prática, interfere e nos ajuda a entender o porquê de certos métodos e comportamentos frente ao ser profissional.

Outra pesquisa, envolvendo narrativa autobiográfica, foi desenvolvida por Santos, Pereira e Lopes (2018), denominada "Experiências da Gestão Acadêmica da Docência Universitária”, publicada na Revista Educação e Realidade, a qual foi realizada com 23 professores de Universidade Públicas do Brasil e de Portugal, entre eles, professores que assumiam cargos de gestão e outros que não assumiam, por meio de uma entrevista, em que o entrevistador transcrevia o que os participantes falavam.

A pesquisa conseguiu constatar diferenças entre as opiniões de professores que têm cargos de gestão e os que não têm. Um exemplo dessas diferenças é que os professores que assumem cargos de gestão consideram necessária a participação efetiva dos outros professores no processo educacional e para a tomada de decisões. Enquanto os professores que não assumem cargos de gestão demonstram um distanciamento dessa preocupação e uma descrença da participação efetiva nas decisões que envolvem a universidade. Além do mais, a pesquisa revelou que a gestão, que poderia ser um espaço de construção de uma identidade 
acadêmica, é recusada porque há um excesso de trabalho não docente, já que esse cargo engloba questões administrativas e burocráticas.

Os pesquisadores destacam que a abordagem narrativa foi fundamental para esse estudo, visto que "valoriza a subjetividade e as experiências pessoais de cada participante" (SANTOS, PEREIRA e LOPES, 2018, p. 7).

Por último, o artigo "Narrativas autobiográficas e representações: o entrelaçar de histórias docentes", de Pacheco (2014), buscou analisar os conceitos de autoridade e autoritarismo, por meio de narrativas orais, de professoras da educação básica, de Santa Maria, Rio Grande do Sul. Por meio das histórias das professoras participantes, puderam discutir, por exemplo, a questão da perda da autoridade e da recuperação da voz docente.

Faz-se interessante destacar que as histórias e experiências não foram escritas, como na maioria das pesquisas aqui resenhadas, foram histórias contadas oralmente.

Nos oito artigos foi possível notar que as narrativas são relevantes tanto para quem conta as experiências e as ressignifica, como também para toda uma comunidade docente, que, ao ter acesso a essas pesquisas, toma conhecimento, compreende a realidade em que vive, reflete e dá outros sentidos ao seu contexto profissional e/ou pessoal.

Por meio desse olhar sobre as pesquisas com autobiografias publicadas, podemos perceber que as experiências vividas e expostas na autobiografia são importantes para visualizarmos as identidades pessoais e/ou profissionais desenvolvidas ao longo da vida. Lembremos que Nóvoa (1992, p. 16) ressalta que a identidade docente não é "um dado adquirido, não é uma propriedade, não é um produto. A identidade é um lugar de lutas e de conflitos, é um espaço de construção de maneiras de ser e estar na profissão" (NÓVOA, 1992, p. 16). Tal asserção é constatada nos artigos resenhados.

Além disso, em concordância com Souza (2013) e Romero (2008), as auto-narrativas dão voz aos professores. Por meio delas, há um engajamento do (futuro) professor em seu próprio processo formativo, visto que há uma ligação direta entre as narrativas e a própria realidade vivenciada.

Por meio dos resultados dessas e de outras pesquisas, que têm como corpus de análise a narrativa autobiográfica, podemos notar também o quão interessante é o uso dessa ferramenta para o desenvolvimento de um olhar crítico e reflexivo, visto que, por intermédio das autobiografias, os docentes têm a possibilidade de descortinar sua realidade, compreender 
os conflitos presentes nessa realidade, e a partir de uma reflexão profunda, serem capazes de atribuir novos sentidos, modificar e transformar o cenário que se encontra.

Ao tomar conhecimento dessas e de outras pesquisas, podemos notar, conforme pontuado antes por Romero (2008), Abrahão (2003), que o método autobiográfico não ocorre de maneira "livre", há a necessidade em terem-se critérios, objetivos ao rememorar e escrever as narrativas, e é por meio desse planejamento do que rememorar e como tratar e discutir o narrado, que conseguimos refletir criticamente. Em outras palavras, a reflexão crítica, que ocorre nesse caso, por meio de narrativas autobiográficas, é uma reflexão dirigida, não ocorre de maneira natural, ou seja, a reflexão é uma ação que se volta a um objetivo e então, o sujeito rememora, compreende, reflete e age sob a realidade.

\section{Considerações finais}

A investigação nos periódicos A1 de educação, que tematizam o uso de narrativas autobiográficas para a formação docente, demonstrou ser significativa, visto que, a partir dos resultados das pesquisas resenhadas, conseguimos compreender a variedade de aspectos que contribuem para estabelecer uma formação crítico-reflexiva, ou seja, como um processo contínuo de se observar, observar a realidade, refletir, questionar e (des)construir-se.

Dentre esses aspectos, destacamos, por exemplo, a possibilidade de compreender o processo de formação das identidades docentes no decorrer da vida pessoal e profissional. Um outro aspecto é a oportunidade em refletir sobre a própria prática e posteriormente agir diante das práticas pedagógicas, modificando-as e melhorando-as quando necessário.

Em suma, com base na análise realizada, percebemos que o uso das narrativas autobiográficas como ferramenta para avaliar a formação docente, propicia investigar os conflitos, compreender uma grande diversidade de as realidades, atribuir novos sentidos às experiências vividas e superar as dificuldades profissionais e/ou pessoais o que constitui, assim, em recurso adequado para o desenvolvimento docente. Naturalmente, causa estranheza, entretanto, haver um número tão baixo de publicações que se utilizem de autobiografias em revistas de Educação.

Assim, esperamos por meio desse trabalho, proporcionar um espaço que oriente outros professores e pesquisadores para o uso das narrativas autobiográficas e, consequentemente, 
promover mudanças referentes ao processo de formação para que sua desejada característica colaborativa e dialética se acentue.

\section{Referências bibliográficas}

ALARCÃO, Isabel. Formação reflexiva de professores: estratégias de supervisão. Porto: Porto Editora, 2005.

ALARCÃO, Isabel. Professores reflexivos em uma escola reflexiva. São Paulo: Cortez, 2007.

ALMEIDA, Raquel S.; GIMENEZ, Telma. A necessidade do professor reflexivo para o uso crítico dos materiais de apoio ao ensino e à aprendizagem de língua estrangeira. Entretextos (UEL), v. 10, p. 69-84, 2010.

BAUMAN, Zygmunt. Identidade. Trad.: Carlos Alberto Medeiros. Rio de Janeiro: Jorge Zahar Ed., 2005.

BRASIL. Ministério da Educação e do Desporto. Parâmetros Curriculares Nacionais Língua Estrangeira. Brasília: MEC, 1998.

BRITO, Daniel B. de. Histórias de vida e saberes docentes das educadoras da Zona Urbana e Rural. Educação \& Realidade, Porto Alegre, v. 40, n. 3, p. 923-945, jul./set. 2015.

CELANI, Maria Antonieta A. Cultura de aprendizagem: risco, incerteza e educação. In MAGALHÃES, M. C. C. A formação do professor como um profissional crítico. Linguagem e reflexão. Campinas/SP: Mercado de Letras, 2004. p 135-160.

FREIRE, Paulo. Pedagogia da autonomia: saberes necessários à prática educativa. São Paulo: Paz e Terra, 1996.

FREIRE, Paulo. Pedagogia do oprimido, 17ª ed. Rio de Janeiro, Paz e Terra, 1987.

FÁVERO, Altair A.; TONIETO, Carina; ROMAN, Marisa F. A formação de professores reflexivos: a docência como objeto de investigação Educação. Revista do Centro de Educação, vol. 38, núm. 2, mayo-agosto, 2013, pp. 277-287 Universidade Federal de Santa Maria Santa Maria, RS, Brasil.

GASTAL, Maria Luiza A.; AVANZI, Maria Rita. Saber da experiência e narrativas autobiográficas na formação inicial de professores de biologia. Ciênc. Educ., Bauru, v. 21, n. 1, p. 149-158, 2015.

GHEDIN, Evandro. Professor reflexivo: da alienação da técnica à autonomia da crítica. In: Selma G. PIMENTA; Evandro GHEDIN (orgs). Professor reflexivo no Brasil: gênese e crítica de um conceito. 3 ed. São Paulo: Cortez, 2005. 
MAIA, Angélica A. M.; MEDRADO Betânia P.; REICHMANN, Carla L. Horizontes e Caminhos para a Escuta de Estagiários: um suleamento necessário. In: C. L. Reichmann e A. L. Guedes-Pinto (orgs.) Horizontes (Im)Possíveis no Estágio: práticas de letramento e formação de professores de línguas. Campinas: Pontes Editores. 2018.

MARTINS, Lígia M.; DUARTE, Newton, orgs. Formação de professores: limites contemporâneos e alternativas necessárias [online]. São Paulo: Editora UNESP; São Paulo: Cultura Acadêmica, 2010. Disponível em: <<http://books.scielo.org/id/ysnm8/pdf/martins9788579831034-05.pdf > . Acesso em: 21/05/2018.

NÓVOA, António. A formação tem que passar por aqui: as histórias de vida no projecto prosalus. In: NÓVOA, António; FINGER, Matthias (Org.). O método (auto)biográfico e a formação. Lisboa: Ministério da Saúde, 1988.

NÓVOA, António. Os professores e sua formação. Lisboa, E. Dom Quixote, 1992.

OLIVEIRA, Luciani S. Estágio Supervisionado: Instância Constitutiva do Ser Professor(a) de Línguas. In: Carla L. Reichmann e Ana L. Guedes-Pinto (orgs.) Horizontes (Im)Possíveis no Estágio: práticas de letramento e formação de professores de línguas. Campinas: Pontes Editores. 2018.

OLIVEIRA, Maria Marly de. Como fazer pesquisa qualitativa. 3ed. Petrópolis: Vozes, 2008, 181p.

PACHECO, Cláudia R. C. Narrativas autobiográficas e representações: o entrelaçar de histórias docentes. Educação, Santa Maria, v. 39, n. 1, p. 51-64, jan./abr. 2014

PERRENOUD, Philippe Formar professores em contextos sociais em mudança. Prática reflexiva e participação crítica. Revista Brasileira de Educação. Set-Dez 1999, n 12, pp. 521.

REICHMANN, Carla L. e ROMERO, Tania R. S. Language Teachers' Narratives and Professional Self-Making. DELTA. Documentação de Estudos em Lingüística Teórica e Aplicada, v. 35, p. 1-25, 2019.

RIOS, Pedro P. S.; BARROS, Edonilce R.; VIEIRA, André R. L. Narrativas de vida e formação de professores gays: (auto) biográficas acerca do estranho que habita em mim. Educação. Santa Maria, v. 42, n. 1, p. 227-240, jan./abr. 2017|

ROMERO, Tania R. de S. Linguagem e memória no construir de futuros professores de inglês. Rev. Brasileira de Linguística Aplicada, v. 8, n. 2, 2008. p. 401-420.

ROMERO, Tania R. de S. Autobiografias de Professores de Inglês: o entretecer de memória e narrativa na constituição da identidade profissional. In: M. A. a. Celani (org.) Reflexões e Ações (Trans) Formadoras no Ensino-Aprendizagem de Inglês. Campinas: Mercado de Letras. 2010. Pp. 141-162. 
ROMERO, Tania R. S.; CASAIS, Allysson A. S. Construção Identitária no Processo de Aprendizagem de Língua e Cultura em Autobiografia de Imigrante. DELTA. Documentação de Estudos em Lingüística Teórica e Aplicada, v. 35, p. 1-28, 2019.

SAVIANI, Dermeval História da formação docente no Brasil: três momentos decisivos. Educação. Revista do Centro de Educação, vol. 30, núm. 2, 2005, pp. 11-26. Universidade Federal de Santa Maria. Santa Maria, RS, Brasil.

Formação de professores: aspectos históricos e teóricos do problema no contexto brasileiro. Revista Brasileira de Educação v. 14 n. 40 jan./abr. 2009.

SHEIBE, Leda. Formação de professores no Brasil A herança histórica. Revista Retratos da Escola, Brasília, v. 2, n. 2-3, p. 41-53, jan./dez. 2008.

SOUZA, Elizeu C. de; ALMEIDA, Joselito Brito. Memórias de educadores baianos: semelhanças e diferenças na constituição da vida na/da escola. In: SOUZA, Elizeu Clementino; PASSEGGI, Maria da Conceição; VICENTINI, Paula Perin (Orgs.). Pesquisa (Auto) biográfica: trajetórias de formação e profissionalização. Curitiba: CRV, 2013, p. 4950 .

SOUZA, Elizeu C. de. Profissionalização, Fabricação de Identidade e Trabalho Docente: Alguns Apontamentos Teóricos. In: Maria Cristina F. Dalacorte, Carla L. Reichmann; Tania R. S. Romero (orgs.). Construções Identitárias de Professores de Línguas. Campinas: Pontes. 2016.

TANURI, Leonor M. O ensino normal no estado de São Paulo: 1890-1930. São Paulo: Faculdade de Educação da USP, 1979.

TANURI, Leonor M. História da formação de professores. Revista Brasileira de Educação, n. 14 , p. 61-88, maio/ago. 2000.

TARDIF, Maurice. Saberes docentes e formação profissional. 17a ed. Petrópolís, RJ: Vozes, 2014.

TEIXEIRA, Anísio S. A educação escolar no Brasil. In: Marialice M. FORACCHI; Luiz PEREIRA. Educação e sociedade: leituras de sociologia da educação. 12 ed. São Paulo: Editora Nacional, 1985. p. 388-413.

ZEICHNER, Kenneth $M$. Uma análise crítica sobre a 'reflexão' como conceito estruturante na formação docente. Educação e Sociedade, vol. 29, no. 103. Campinas, maio/agosto 2008 . 